\title{
Cisplatin-incorporated nanoparticles of poly(acrylic acid-co-methyl methacrylate) copolymer
}

This article was published in the following Dove Press journal:

International Journal of Nanomedicine

7 August 2013

Number of times this article has been viewed

\section{Kyung Dong Lee ${ }^{1, *}$ \\ Young-II Jeong 2,* $^{2}$ \\ Da Hye Kim ${ }^{3,4}$ \\ Gyun-Taek Lim² \\ $\mathrm{Ki}-$ Choon $\mathrm{Choi}^{5}$}

'Department of Oriental Medicine Materials, Dongshin University, Naju, South Korea; ${ }^{2}$ Department of Polymer Engineering, Chonnam National University, Gwangju, South Korea; ${ }^{3}$ Faculty of Life and Environmental Science, Shimane University,

Matsue, Japan; ${ }^{4}$ United Graduate School of Agricultural Sciences,

Tottori University, Tottori, Japan;

${ }^{5} \mathrm{Grassland}$ and Forages Division,

National Institute of Animal Science, Rural Development Administration,

Cheonan, South Korea

*These authors contributed equally to this work
Correspondence: Ki-Choon Choi Grassland and Forages Division, National Institute of Animal Science, Rural Development Administration, 9 Eoryong-ri, Seonghwan-eup, Cheonan, Chungnam 331-808, South Korea

Tel +82 4I 5806752

Fax +82 4I 5806779

Email choiwh@rda.go.kr
Background: Although cisplatin is extensively used in the clinical field, its intrinsic toxicity limits its clinical use. We investigated nanoparticle formations of poly(acrylic acid-co-methyl methacrylate) (PAA-MMA) incorporating cisplatin and their antitumor activity in vitro and in vivo.

Methods: Cisplatin-incorporated nanoparticles were prepared through the ion-complex formation between acrylic acid and cisplatin. The anticancer activity of cisplatin-incorporated nanoparticles was assessed with CT26 colorectal carcinoma cells.

Results: Cisplatin-incorporated nanoparticles have small particle sizes of less than $200 \mathrm{~nm}$ with spherical shapes. Drug content was increased according to the increase of the feeding amount of cisplatin and acrylic acid content in the copolymer. The higher acrylic acid content in the copolymer induced increase of particle size and decrease of zeta potential. Cisplatin-incorporated nanoparticles showed a similar growth-inhibitory effect against CT26 tumor cells in vitro. However, cisplatin-incorporated nanoparticles showed improved antitumor activity against an animal tumor xenograft model.

Conclusion: We suggest that PAA-MMA nanoparticles incorporating cisplatin are promising carriers for an antitumor drug-delivery system.

Keywords: cisplatin, nanoparticle, poly(acrylic acid-co-methyl methacrylate), ion complexes

\section{Introduction}

Cisplatin has been extensively used for clinical treatment of various tumors. ${ }^{1}$ However, its treatment regimen in the clinical field needs to be improved or altered, because cisplatin has severe toxicity against the human body, eg, acquired resistance, acute nephrotoxicity, and chronic neurotoxicity. ${ }^{2,3}$ Novel drug-delivery systems based on nanoparticles, liposomes, polymeric micelles, and polymer conjugates have been proposed as promising vehicles for delivery of cisplatin to tumors and for reduction of neuro-/nephrotoxicity. ${ }^{4-9}$ Polymeric micelles incorporating cisplatin were reported to have improved anticancer activity, reduced intrinsic toxicity, and prolonged blood circulation. ${ }^{4,5}$ Cisplatin-incorporated polymeric micelles were based on ion complexation between cisplatin and anionic polymers. ${ }^{4}$ Their polymeric micelles revealed significant reduction in intrinsic toxicity of cisplatin, with improvement in anticancer effect against an animal tumor xenograft model. Nanoparticles based on cisplatin/ carboxymethyl cellulose core and poly(lactide-co-glycolide)-methoxy-poly(ethylene glycol) copolymers were also reported to improve anticancer activity and reduce toxicity. ${ }^{6}$ Leite et al reported that $\mathrm{pH}$-sensitive liposomes were effective in reducing mass of 
solid tumors in mice and intrinsic toxicity of drugs. ${ }^{7}$ Sonoda et al reported on dextran magnetite-conjugated cisplatin for hyperthermic treatment of solid tumors. ${ }^{8}$ In this report, they obtained magnetic accumulation of dextran magnetiteconjugated cisplatin with hyperthermic effects.

The aim of this study was to investigate the potential of cisplatin-incorporated nanoparticles using poly(acrylic acidco-methyl methacrylate) (PAA-MMA) copolymer against CT26 colon carcinoma cells. Since PAA-MMA has plenty of carboxylic acid moieties, nanoparticles incorporating cisplatin can be formed through ion complexation between cisplatin and PAA. We investigated the physicochemical properties of the PAA-MMA nanoparticles incorporating cisplatin, and their antitumor activity was evaluated against CT26 color rectal carcinoma cells in vitro and in vivo.

\section{Materials and methods}

\section{Materials}

Sodium acrylate (AA), methyl methacrylate (MMA), poly(ethylene glycol) diacrylate (PEGDA; molecular weight $\left.\left[\mathrm{M}_{\mathrm{w}}\right] 575 \mathrm{~g} / \mathrm{mol}\right)$, dialysis tubing $\left(\mathrm{M}_{\mathrm{w}}\right.$ cutoff $\left.12,000 \mathrm{~g} / \mathrm{mol}\right)$, dimethylformamide (DMF), and dimethyl sulfoxide (DMSO) were purchased from Sigma-Aldrich (St Louis, MO, USA). DMF and DMSO was used as extra-pure grade. Cisplatin was purchased from Wako Pure Chemical Industries (Osaka, Japan).

\section{Synthesis of PAA-MMA copolymer}

PAA-MMA sodium salt was synthesized in deionized water by free radical emulsion polymerization, as previously reported. ${ }^{10}$ Briefly, AA and MMA were polymerized in the presence of $100 \mathrm{mg}$ ammonium persulfate (APS) as a crosslinker and 100 microliter PEGDA as an initiator. The monomers and chemicals in a round-bottomed flask were stirred at $900 \mathrm{rpm}$ at $65^{\circ} \mathrm{C}$ for 6 hours under nitrogen gas atmosphere. In this reaction, the feed molar ratio of AA versus MMA ranged from 0.7 to 0.9 . The resulting solution was centrifuged at 100,000 $\mathrm{g}$ for 30 minutes and dried in a vacuum. White solid was placed in a refrigerator until use.

\section{Analysis of PAA-MMA copolymer}

The $\mathrm{M}_{\mathrm{w}}$ of copolymer was evaluated by gel-permeation chromatography (GPC). The GPC system was composed of a 515 HPLC pump, 410 differential refractometer, 486 tunable absorbance detector, and ultrahydrogel 250 and 2000 columns $(7.8 \mathrm{~mm}$ inner diameter $\times 30 \mathrm{~cm}$, flow rate $1.0 \mathrm{~mL} / \mathrm{minute}$ ) (all Waters, Milford, MA, USA). The experimental conditions were as follows: mobile phase
$0.1 \mathrm{NaNO}_{3}$, flow rate $1.0 \mathrm{~mL} /$ minute, laser wavelength $690 \mathrm{~nm}$, temperature $60^{\circ} \mathrm{C}$. Polyethylene glycol (PEG) was used to determine $\mathrm{M}_{\mathrm{w}}$ as a standard.

\section{Preparation of cisplatin-incorporated nanoparticles}

PAA-MMA $100 \mathrm{mg}$ was dissolved in $10 \mathrm{~mL}$ deionized water. To this solution, 5-20 mg of cisplatin was added as a solid form. This mixture was stirred gently for 3 days under dark conditions. Since cisplatin itself is not soluble in deionized water, it was dispersed in the aqueous solution of PAA-MMA copolymer as a solid form. At least 2 days were required to dissolve cisplatin in PAA-MMA solution and to form nanoparticles. After that, this solution was dialyzed against deionized water for 6 hours to remove the salt and unloaded drug. The dialyzed solution was used to analyze or lyophilize.

The cisplatin-entrapped nanoparticles were kept in $0.3 \mathrm{M} \mathrm{NaCl}$ at $37^{\circ} \mathrm{C}$ for 3 days to liberate whole cisplatin from nanoparticles. Then, this solution was diluted ten times with DMF. An ultraviolet (UV) spectrophotometer (UV1201; Shimadzu, Kyoto, Japan) was employed to evaluate the content and loading efficiency of the cisplatin in the nanoparticles at $310 \mathrm{~nm}^{9}$

The drug contents and loading efficiency were evaluated using the following equations:

Drug content $=($ Amount of liberated cisplatin from the nanoparticles/Weight of nanoparticles) $\times 100$

Loading efficiency $=($ Liberated amount of cisplatin from the nanoparticles/Feeding amount of cisplatin) $\times 100$

\section{Analysis of cisplatin-incorporated nanoparticles}

The morphology of cisplatin-incorporated nanoparticles was observed with transmission electron microscopy (TEM). A drop of polymeric micelle suspension was placed onto a carbon film coated on a copper grid for TEM observation. The observation was performed at $80 \mathrm{kV}$ in a JEM-2000 FX II (JEOL, Tokyo, Japan).

The particle size of the cisplatin-incorporated nanoparticles was assessed with dynamic laser scattering (DLS-7000; Otsuka Electronics, Hirakata, Japan). The zeta potential of the nanoparticles was measured using photon correlation spectroscopy (Zetasizer 3000; Malvern Instruments, Malvern, UK) with an $\mathrm{He}-\mathrm{Ne}$ laser beam at a wavelength of $633 \mathrm{~nm}$ at $25^{\circ} \mathrm{C}$ (scattering angle of $90^{\circ}$ ). 


\section{Drug-release study}

Nanoparticles $(10 \mathrm{mg}$ ) were reconstituted in $3 \mathrm{~mL}$ deionized water, and this solution was put into a dialysis tube $\left(\mathrm{M}_{\mathrm{w}}\right.$ cutoff $\left.12,000 \mathrm{~g} / \mathrm{mol}\right)$. Then, the dialysis tube was put into a $50 \mathrm{~mL}$ Falcon tube with $37 \mathrm{~mL}$ phosphate-buffered saline (PBS; pH 7.4, 0.01 M). Cisplatin was released at $100 \mathrm{rpm}$ and $37^{\circ} \mathrm{C}$. Two milliliters of the sample solution was taken at predetermined time intervals for measurement of drug release, and the solution was supplemented with $2 \mathrm{~mL}$ fresh medium. The release amount of cisplatin was measured with the UV spectrophotometer at $310 \mathrm{~nm}$. For comparison, $2 \mathrm{mg}$ free cisplatin was added to $5 \mathrm{~mL}$ PBS and magnetically stirred for 6 hours. After that, this solution was introduced into a dialysis tube and a release test performed. For blank testing, PAA-MMA was dissolved in PBS and release testing performed similar to the above method. All experiments were performed in triplicate, and the results were expressed as means \pm standard deviation.

\section{Cell-culture study}

For the anticancer activity of cisplatin and its nanoparticles, CT26 colorectal carcinoma cells were used throughout this study. CT26 cells were maintained in a $5 \% \mathrm{CO}_{2}$ incubator $\left(37^{\circ} \mathrm{C}\right)$ with Roswell Park Memorial Institute (RPMI) 1640 medium supplemented with $10 \%$ fetal bovine serum (FBS) and 1\% antibiotics.

\section{Anticancer activity of cisplatin- incorporated nanoparticles in vitro}

The anticancer activity of cisplatin-incorporated nanoparticles was assessed in vitro using the MTT (3-[4,5-dimethylthiazol-2-yl]-2,5-diphenyltetrazolium bromide) cell-proliferation assay. A total $3 \times 10^{3}$ CT26 cells were seeded onto 96-well plates and incubated overnight in a $5 \% \mathrm{CO}_{2}$ incubator at $37^{\circ} \mathrm{C}$. Cisplatin dissolved in DMSO was diluted with RPMI 1640 medium supplemented with $10 \%$ FBS (final concentration of DMSO was less than $0.5 \%, \mathrm{v} / \mathrm{v}$ ) and treated in $96-$ well plates. Cisplatinincorporated nanoparticles reconstituted in deionized water were diluted ten times with RPMI 1640 medium supplemented with FBS. DMSO (final concentration: $0.5 \%, \mathrm{v} / \mathrm{v}$ ) was treated as a control. For comparison, PAA-MMA dissolved in deionized water was diluted ten times with RPMI 1640 medium supplemented with $10 \%$ FBS and treated with tumor cells. The tumor cells were incubated for an additional 48 hours at $37^{\circ} \mathrm{C}$ in a $5 \% \mathrm{CO}_{2}$ incubator. $25 \mu 1$ of MTT (3 mg/mL in PBS) was added to
96 well plates and then the cells were further incubated for 4 hours. Subsequently, $100 \mu 1$ sodium dodecyl sulfate (SDS)-hydrogen chloride $(\mathrm{HCl})$ solution $(\mathrm{SDS} 10 \% \mathrm{w} / \mathrm{v}$, $0.01 \mathrm{M} \mathrm{HCl}$ ) was added to each well and incubated for an additional 12 hours at $37^{\circ} \mathrm{C}$ in a $5 \% \mathrm{CO}_{2}$ incubator. The absorbance was then measured at a wavelength of $570 \mathrm{~nm}$ using an Infinite M200 Pro reader (Tecan Austria, Salzburg, Austria). The viable cells were expressed as a percentage of control. The results were calculated from the eight wells as the means \pm standard deviation of three different experiments.

\section{Apoptosis/necrosis analysis of tumor cells}

Apoptosis and necrosis of tumor cells were analyzed with a flow cytometer. Fluorescein isothiocyanate (FITC) annexin V (sc-4252 FITC; Santa Cruz Biotechnology, Santa Cruz, CA, USA) was used to analyze apoptosis of cells, and propidium iodide (PI) reagents (P4170; Sigma-Aldrich) were used to identify necrosis of tumor cells. Cells were exposed to cisplatin or cisplatin-incorporated nanoparticles for 24 hours and then harvested. The harvested cells were resuspended in binding buffer (10 $\mathrm{mM} 4$-[2-hydroxyethyl]1-piperazineethanesulfonic acid, $\mathrm{pH} 7.4,150 \mathrm{mM} \mathrm{NaCl}$, $5 \mathrm{mM} \mathrm{KCl}, 1 \mathrm{mM} \mathrm{MgCl}$, and $1.8 \mathrm{mM} \mathrm{CaCl}_{2}$ ) containing FITC annexin $\mathrm{V}(1 \mathrm{~g} / \mathrm{mL})$ and then further incubated for 20 minutes. Ten minutes before the end of incubation, PI $(10 \mathrm{~g} / \mathrm{mL})$ was added to this cell suspension in order to stain necrotic cells. Cells were analyzed with a FACScan flow cytometer (BD Biosciences, San Jose, CA, USA) equipped with an excitation laser line at $488 \mathrm{~nm}$. The PI was collected through a $575 \pm 15 \mathrm{~nm}$ band-pass filter.

\section{Anticancer activity of cisplatin- incorporated nanoparticles in vivo}

CT26 cells $\left(2 \times 10^{4}\right.$ cells/mouse $)$ were implanted subcutaneously into the back of BALB/c nude mice ( 5 weeks old, approximately $20 \mathrm{~g}$ ). When the size of solid tumors in the backs of mice reached approximately $3 \times 3 \mathrm{~mm}$, mice were divided into four groups: the control group was injected with PBS, the drug-treatment group was injected with cisplatin (cisplatin in PBS), the vehicle-treatment group was injected with PAA-MMA polymer (PAA-MMA-1 dissolved in PBS), and the nanoparticle-treatment group was injected with cisplatin-incorporated nanoparticles. Each group consisted of five ear-tagged tumor-bearing mice and was followed up throughout the study. The administration of cisplatin, vehicle, or nanoparticles began on day 14. Cisplatin or nanoparticles were administered at doses of $5 \mathrm{mg} / \mathrm{kg}$, 
and vehicle (PAA-MMA-1) was administered at doses of $50 \mathrm{mg} / \mathrm{kg}$. Mortality was monitored daily, and tumor growth was measured at 3-day intervals by caliper measurement. Tumor volume was calculated as follows: tumor volume $\left(\mathrm{mm}^{3}\right)=\left(\right.$ length $\times$ width $\left.^{2}\right) / 2$. Animal experiments using nude mice were conducted in an aseptic environment, and all experiments were performed according to the guidelines approved by the Committee for the Care and Use of Laboratory Animals at Chonnam National University.

\section{Statistical analysis}

Student's $t$-test (SigmaPlot; Systat, San Jose, CA, USA) was used to assess the statistical differences between experimental groups. $P<0.05$ was taken as being statistically significant.

\section{Results}

\section{Synthesis and characterization of PAA-MMA copolymer}

PAA-MMA copolymer having various ratios of AA:MMA was synthesized by free radical emulsion polymerization, as described by Yan and Gemeinhart. ${ }^{10}$ As shown in Figure 1, the AA:MMA ratio changed from $7: 3$ to $9: 1$, and single peaks obtained about 8 minutes of retention time. Average $\mathrm{M}_{\mathrm{w}}$ of PAA-MMA is presented in Table 1, and this was about $114,400-136,900$.

\section{Preparation and characterization of cisplatin-incorporated nanoparticles}

Nanoparticles of PAA-MMA copolymer incorporating cisplatin were prepared via ion-complex formation between

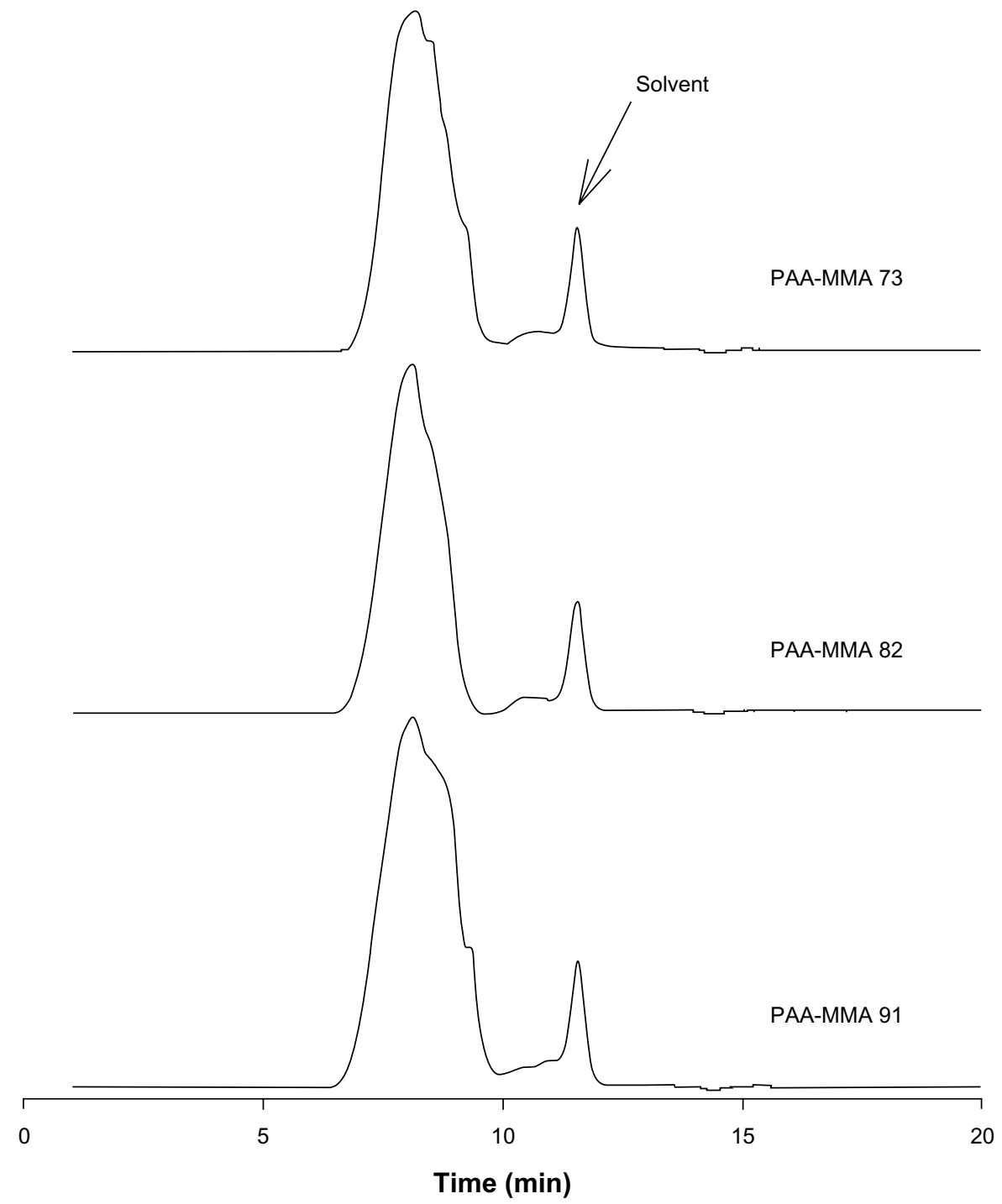

Figure I Gel-permeation chromatography profiles of poly(acrylic acid-co-methyl methacrylate) (PAA-MMA) copolymer. Polyethylene glycol as a standard was used for evaluation of molecular weight. 
Table I Characterization of PAA-MMA copolymers

\begin{tabular}{lllll}
\hline & $\begin{array}{l}\text { Mole ratio of } \\
\text { AA:MMA }\end{array}$ & \multicolumn{2}{c}{ Molecular weight } & PDI \\
\cline { 3 - 4 } & $\mathbf{M}_{\mathbf{n}}$ & $\mathbf{M}_{\mathbf{w}}$ & \\
\hline PAA-MMA-I & $7: 3$ & 124,200 & 136,900 & $1.102 \pm 0.130$ \\
PAA-MMA-2 & $8: 2$ & 96,530 & 119,700 & $1.240 \pm 0.101$ \\
PAA-MMA-3 & $9: 1$ & 87,000 & 114,400 & $1.315 \pm 0.167$ \\
\hline
\end{tabular}

Abbreviations: $M_{n}$, number-average molecular weight; $M_{w}$, weight-average molecular weight; PDI, polydispersity index; AA, sodium acrylate.

carboxylic acid of PAA-MMA copolymer and cisplatin, as shown in Figure 2. Cisplatin as a solid form was added to an aqueous solution of PAA-MMA copolymer and stirred for 3 days until a transparent aqueous solution was obtained. Even though cisplatin is not soluble in deionized water, it was completely dissolved in an aqueous solution of PAA-MMA copolymer when cisplatin was complexed with PAA-MMA copolymers and formed nanoparticles, as depicted in Figure 2. This solution was used to identify nanoparticle formation between PAA-MMA and cisplatin using dynamic light scattering and TEM. As shown in Figure 3, spherical particles were observed from this aqueous solution, and their average particle size was around $150 \mathrm{~nm}$ (PAA-MMA-2-2 in Table 2). To assess nanoparticle formation, the feeding ratio of cisplatin/ PAA-MMA copolymer and series of copolymers was changed, as shown in Table 2. When the feeding amount of cisplatin was increased, particle size increased from $114 \mathrm{~nm}$ to $158 \mathrm{~nm}$, and zeta potential also increased. Drug contents were increased according to the increase of feeding amount of cisplatin and AA content in the copolymer Higher AA content in the copolymer induced increase in particle size and decrease in zeta potential. Since PAAMMA copolymer with higher AA content has a higher anionic domain, the zeta potential of nanoparticles should be decreased.

Figure 4 shows cisplatin release from nanoparticles of the PAA-MMA copolymer. As shown in Figure 4A, AA content in the copolymer composition did not significantly change the cisplatin-release rate from PAA-MMA nanoparticles, even though PAA-MMA-3 had a slightly higher release rate than the other formulations. At all formulations, the initial burst effect was observed until 12 hours, and then cisplatin was continuously released from nanoparticles. Otherwise, the higher cisplatin content resulted in a slower release rate than the lower cisplatin content in the nanoparticles, as shown in Figure 4B. For comparison, release of free cisplatin was also studied in vitro. As shown in Figure 4B, most of the free cisplatin was liberated within 24 hours, indicating that nanoparticles have the potential to release cisplatin in a sustained manner.

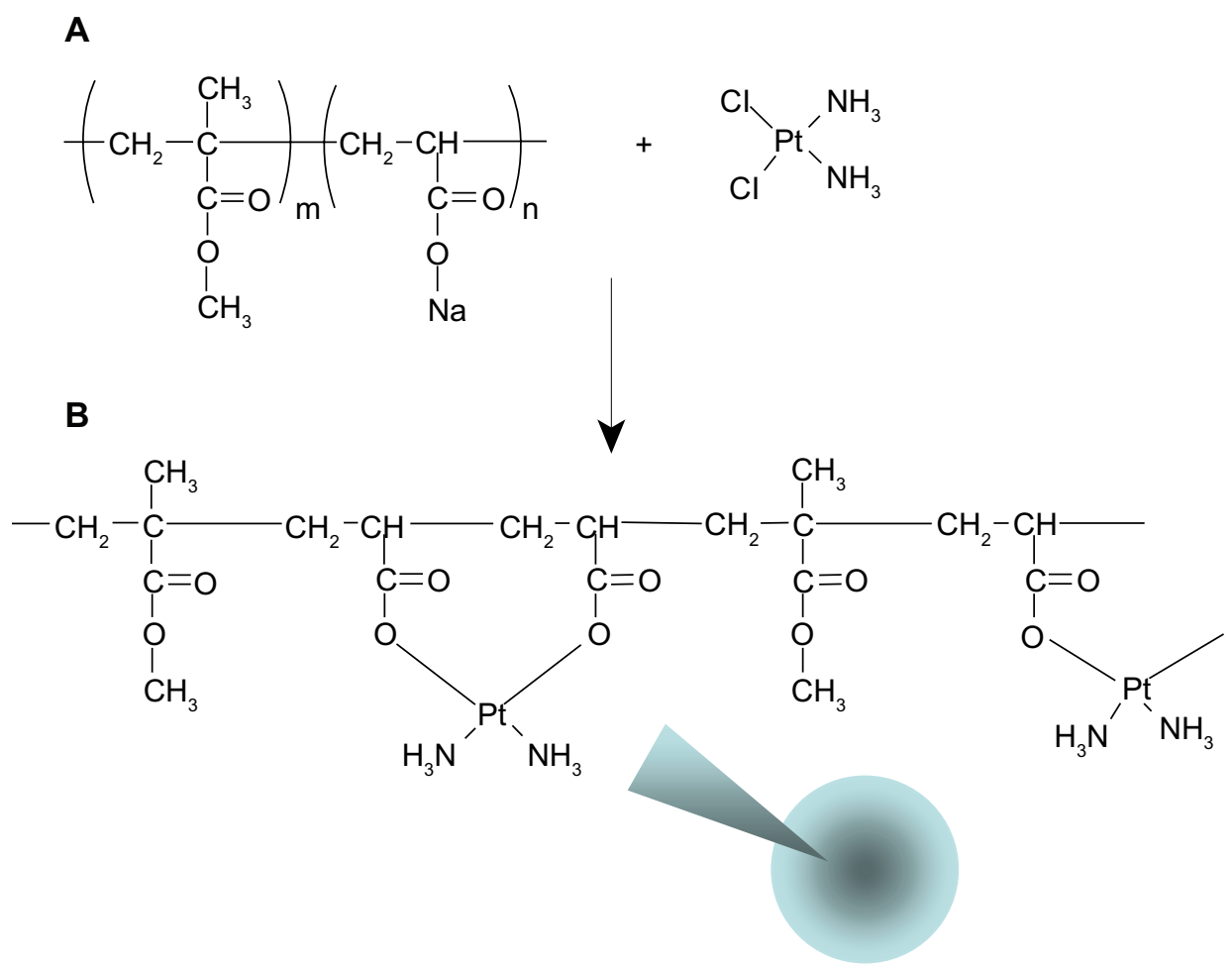

Figure 2 Structure of poly(acrylic acid-co-methyl methacrylate) copolymer (A) and schematic illustration of ion-complex formation between carboxylic acid and cisplatin (B). 
A

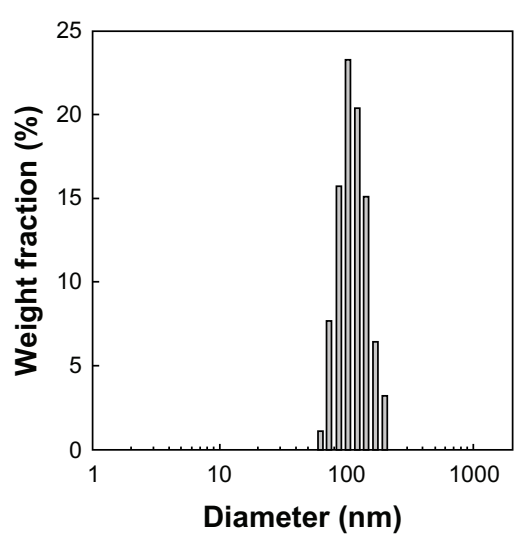

B

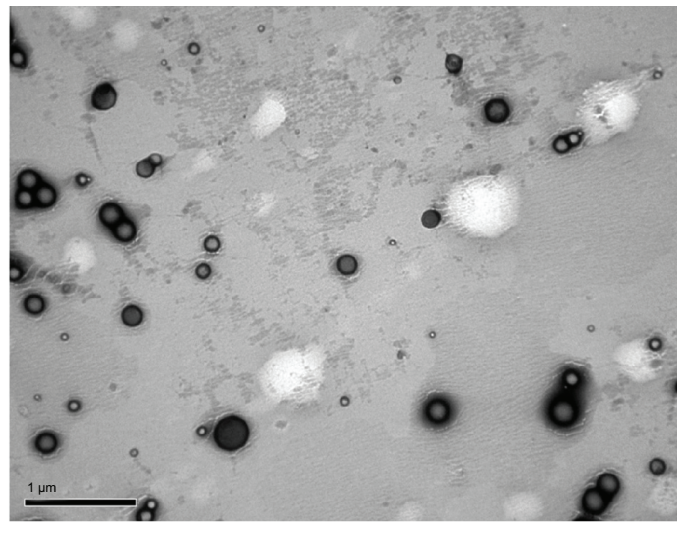

Figure 3 Typical particle size (A) and transmission electron microscopy of cisplatin-incorporated nanoparticles (B) (PAA-MMA-2-2 in Table 2).

\section{Anticancer activity of cisplatin- incorporated nanoparticles}

To investigate the antitumor activity of cisplatin-incorporated nanoparticles, free cisplatin, cisplatin-incorporated nanoparticles, and vehicles (PAA-MMA copolymer) were used to treat CT26 tumor cells, and growth inhibition was assessed in vitro. As shown in Figure 5, cisplatin showed a dosedependent growth-inhibitory effect against CT26 cells. Interestingly, nanoparticles incorporating cisplatin showed a practically similar inhibitory effect on the growth of tumor cells, as shown in Figure 5A. Furthermore, the differences between series of PAA-MMA nanoparticles did not significantly change the growth of tumor cells. PAA-MMA copolymer itself did not significantly inhibit growth of tumor cells, as shown in Figure 5B. These results indicated that PAA-MMA nanoparticles incorporating cisplatin have at least similar anticancer activity in vitro.

Figures 6 and 7 show apoptosis and necrosis analysis of CT26 cells. Figure 6 shows the effect of cisplatin and cisplatin-incorporated nanoparticles on the apoptosis of CT26 cells. As shown in Figure 6, apoptotic cells were increased dose-dependently with both treatments of cisplatin and cisplatin-incorporated nanoparticles. PAA-MMA copolymer itself did not significantly affect the apoptosis of tumor cells. Figure 7 shows the necrosis of tumor cells. These results also showed that necrotic cells were increased dose-dependently by both treatments of cisplatin and cisplatin-incorporated nanoparticles, while PAA-PMMA copolymer itself did not affect the necrosis of tumor cells. These results indicated that cisplatin-incorporated nanoparticles induce apoptosis/necrosis of tumor cells as well as free cisplatin.

The antitumor activity of cisplatin-incorporated nanoparticles was assessed in vivo using CT26-bearing mice. CT26 cells were implanted in the backs of the mice. About 2 weeks later, cisplatin, cisplatin-incorporated nanoparticles, and vehicles were administered intravenously. As shown in Figure 8, control and vehicle treatment showed a rapid increase of tumor mass, while cisplatin inhibited tumor growth compared to the control treatment. Interestingly, cisplatin-incorporated nanoparticles showed the highest inhibitory effect on the growth of tumor mass. PAA-MMA itself had practically no inhibitory effect on tumor growth. These results indicated that PAA-MMA has promising anticancer activity against an animal tumor xenograft model.

Table 2 Characterization of cisplatin-incorporated nanoparticles

\begin{tabular}{|c|c|c|c|c|c|}
\hline & \multirow{2}{*}{$\begin{array}{l}\text { Polymer: } \\
\text { cisplatin ratio } \\
\text { (mg/mg) }\end{array}$} & \multicolumn{2}{|c|}{ Drug contents $(\%, w / w)$} & \multirow{2}{*}{$\begin{array}{l}\text { Particle } \\
\text { size } \\
(\mathrm{nm})\end{array}$} & \multirow{2}{*}{$\begin{array}{l}\text { Zeta } \\
\text { potential } \\
(\mathrm{mV})\end{array}$} \\
\hline & & Theoretical & Experimental & & \\
\hline PAA-MMA-I & $100: 10$ & 9.1 & 4.7 & $149.8 \pm 25.4$ & -5.80 \\
\hline PAA-MMA-2-I & $100: 5$ & 4.8 & 2.3 & $114.3 \pm 30.1$ & -7.84 \\
\hline PAA-MMA-2-2 & $100: 10$ & 9.1 & 4.9 & $150.7 \pm 22.2$ & -6.52 \\
\hline PAA-MMA-2-3 & $100: 20$ & 16.7 & 10.6 & $158.8 \pm 24.3$ & -4.05 \\
\hline PAA-MMA-3 & $100: 10$ & 9.1 & 5.3 & $163.1 \pm 28.9$ & $-|6.3|$ \\
\hline
\end{tabular}

Abbreviation: PAA-MMA, poly(acrylic acid-co-methyl methacrylate). 

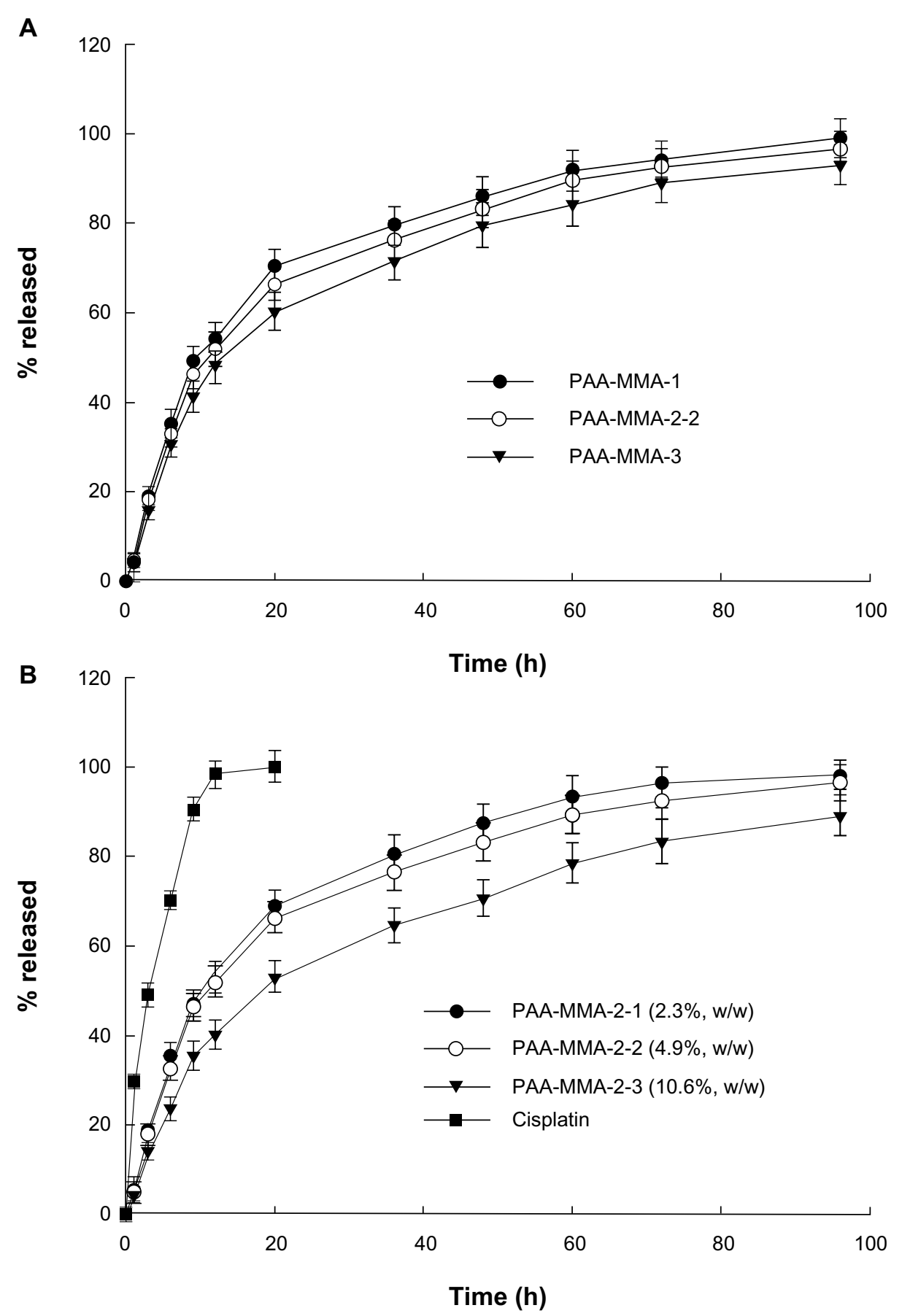

Figure 4 The effect of copolymer ratio (A) and drug contents $(\mathbf{B})$ on the drug release from nanoparticles. Abbreviation: PAA-MMA, poly(acrylic acid-co-methyl methacrylate).

\section{Discussion}

The formation of nanocomplexes between carboxylic acid and cisplatin has been extensively investigated for the last decade. ${ }^{4,511}$ Pioneering studies have been performed in the polymeric micelle formation of ion complexes between cisplatin and PEG-poly(aspartic acid) block copolymer., ${ }^{4,512}$ Basically, chloride groups of cisplatin were replaced with sodium carboxylate of polymer, and then nanocomplexes were formed, as shown in Figure 2. They reported that stable micellar solution can be prepared by a simple mixture of cisplatin solid and aqueous polymer solution. ${ }^{4}$ They obtained stable core-shell polymeric micelles incorporating cisplatin because they used block copolymer composed of PEG and poly(aspartic acid), ie, poly(aspartic acid) was complexed with cisplatin and then formed the inner core of the polymeric micelles, while PEG formed the outer shell. In our case, plain 
A
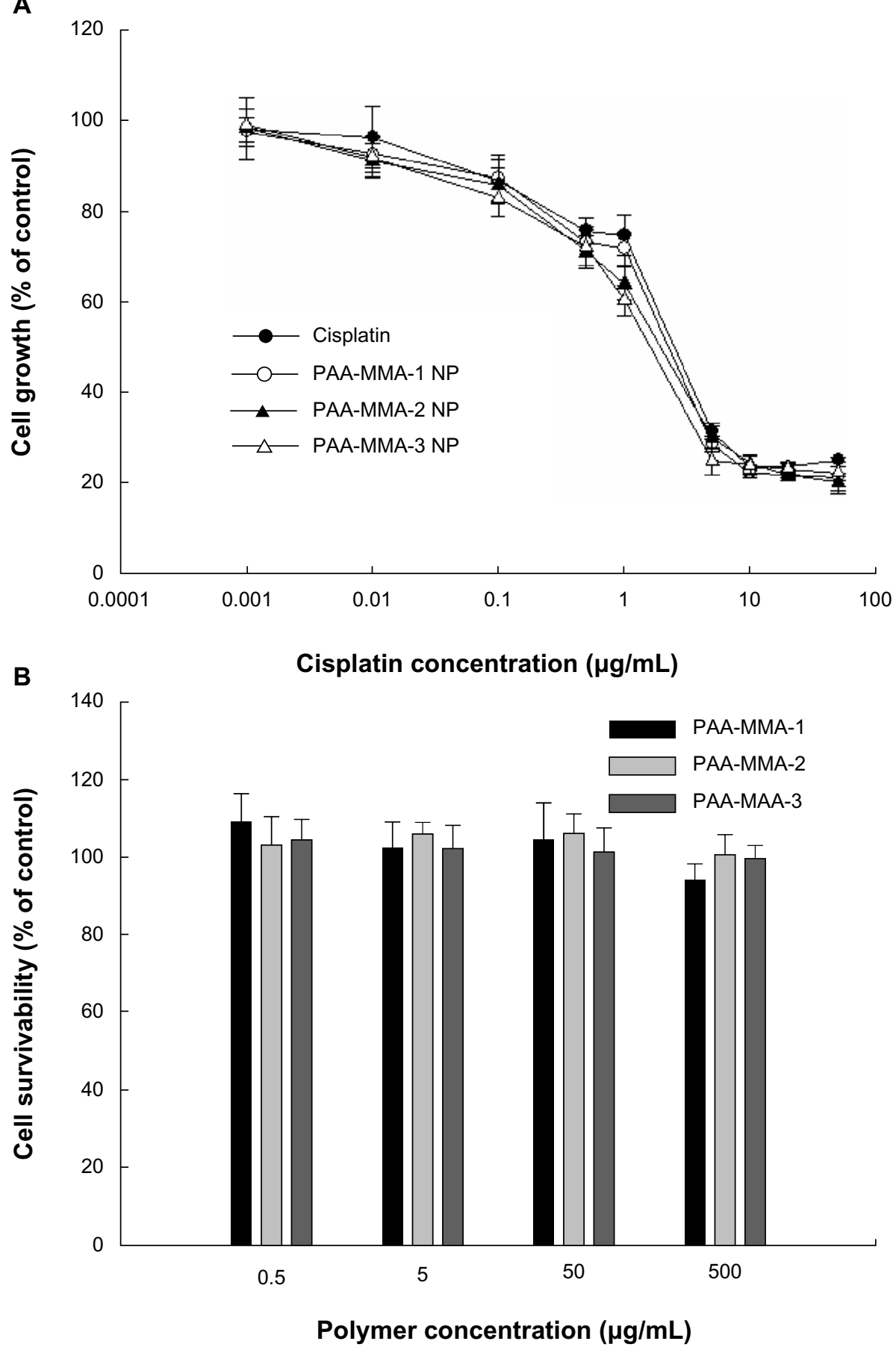

Figure 5 Cytotoxicity of cisplatin or cisplatin-incorporated nanoparticles (NPs) (A) and poly(acrylic acid-co-methyl methacrylate) (PAA-MMA) copolymer (B). Cisplatin, cisplatin-incorporated NPs, and PAA-MMA copolymer were exposed to CT26 cells for 2 days.

nanoparticles incorporating cisplatin were formed because PAA-MMA is a random copolymer.

It has been proved that sustained release formulations of cisplatin such as nanoparticles or polymeric micelles lowered intrinsic toxicity against human body in a Phase I clinical trial. ${ }^{12}$ Furthermore, Jeong et al reported that cisplatin and hyaluronic acid (HA) can form nanocomplexes, and cisplatin release can be controlled by enzymatic degradation of HA. ${ }^{11}$ They argued that the release rate of cisplatin from nanoparticles became faster in the presence of hyaluronidase and these properties target the modality of cisplatin-HA nanocomplexes.

We synthesized PAA-MMA copolymer with various ratios of AA/MMA to incorporate cisplatin through an ion-complex formation. Aqueous solution of a PAA-MMA 


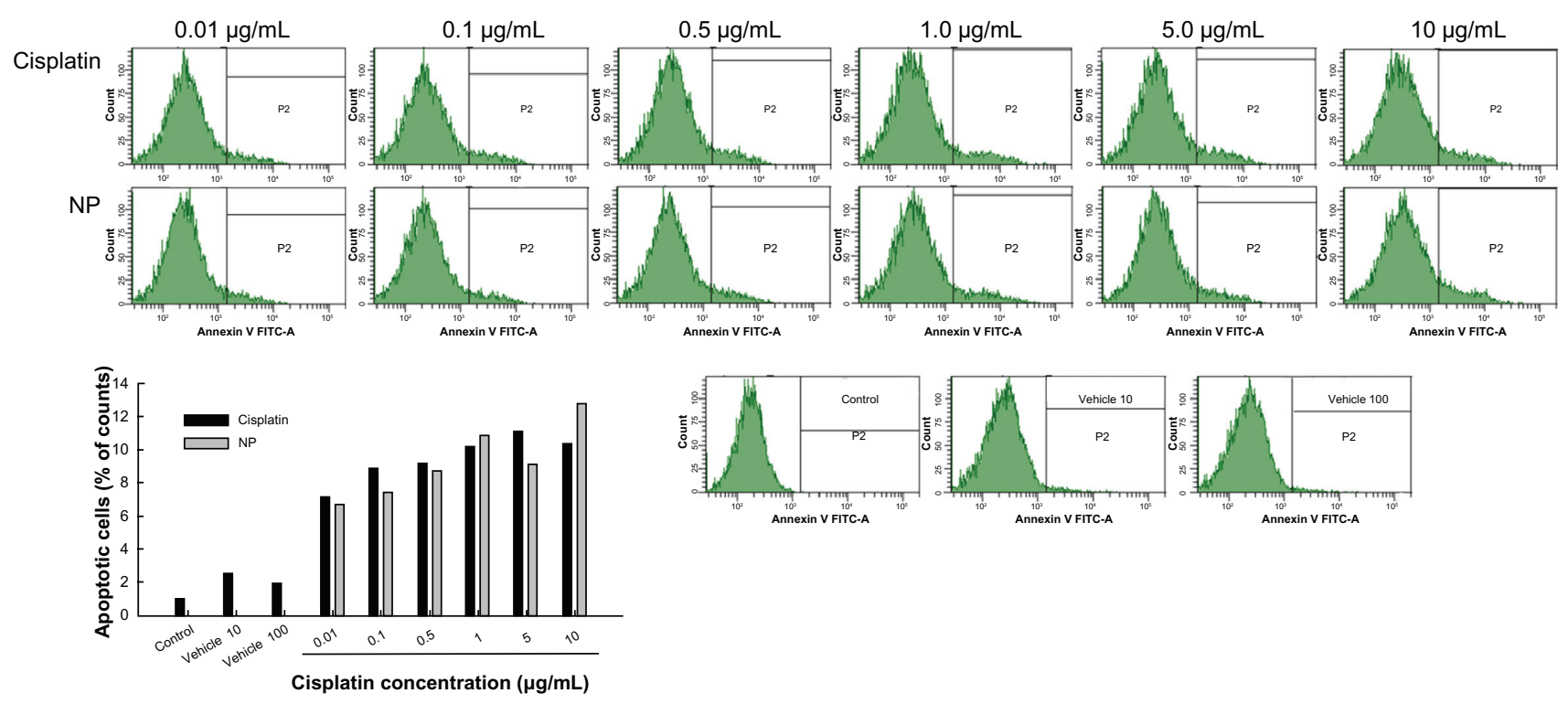

Figure 6 Apoptosis and necrosis analysis of CT26 cells after treatment with cisplatin or cisplatin-incorporated (poly[acrylic acid-co-methyl methacrylate]-2-3) nanoparticles (NPs) for I day. Cells were stained with fluorescein isothiocyanate (FITC) annexin V for apoptosis analysis.

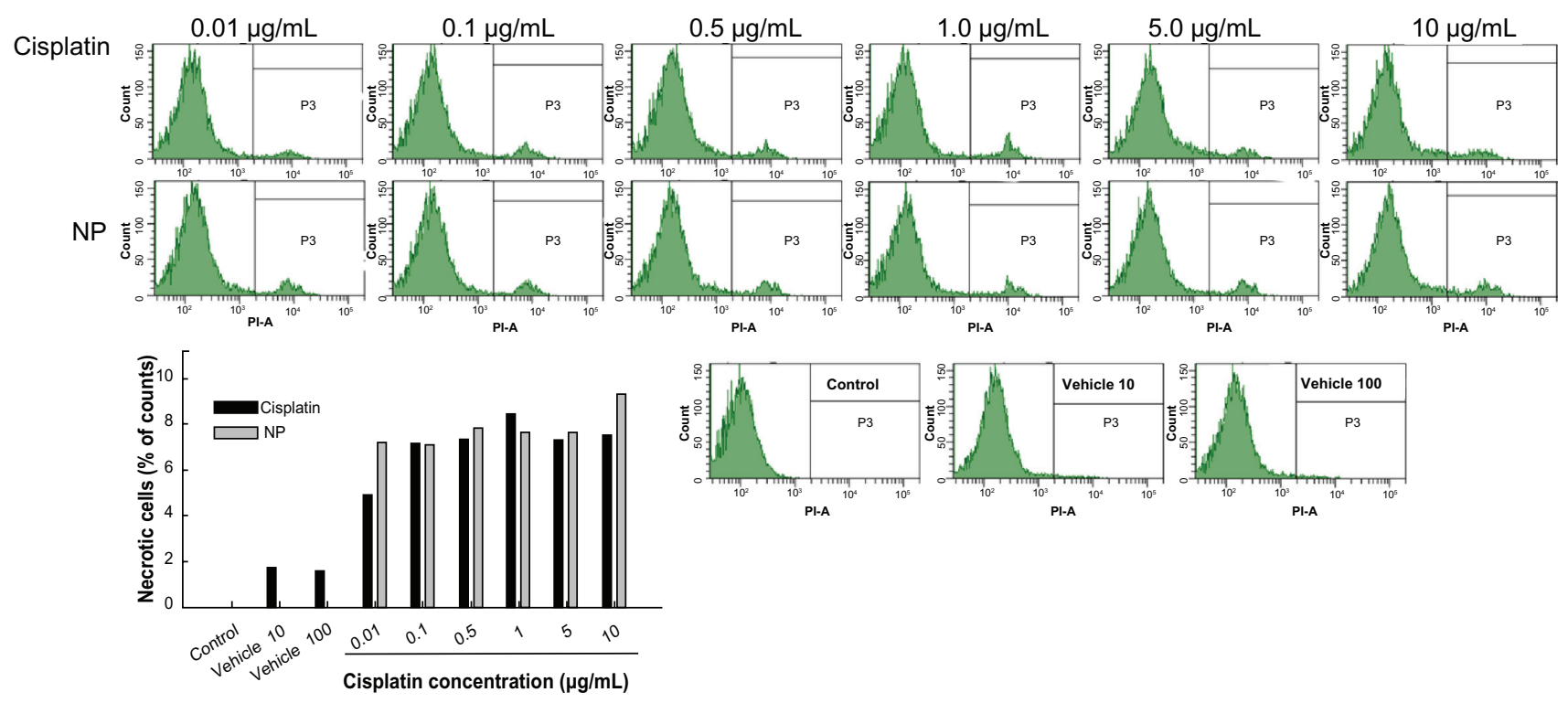

Figure 7 Necrosis analysis of CT26 cells after treatment with cisplatin or cisplatin-incorporated (poly[acrylic acid-co-methyl methacrylate]-2-3) nanoparticles (NPs) for I day. Cells were stained with propidium iodide $(\mathrm{PI})$ for necrosis analysis.

copolymer was mixed with cisplatin solid, and nanoparticles were formed by ion complexation between sodium carboxylate of AA and a chloride group of cisplatin. Yan and Gemeinhart reported the formation of submicron particles between PAA-MMA copolymer and cisplatin. ${ }^{10}$ Our work was stimulated by their in vitro study for the precise characteristics of submicron particles incorporating cisplatin. They described that cisplatin-incorporated microparticles were fabricated using PAA-MMA copolymer, and diameters of cisplatin-incorporated microparticles were in the range of $500 \mathrm{~nm}-2,300 \mathrm{~nm}$. Furthermore, they described that PAA-MMA microparticles incorporating cisplatin have significantly lower cytotoxicity against NIH/3T3 cells and lower acute toxicity against small animals (female rats) than cisplatin. However, they did not describe antitumor activity of cisplatin-incorporated microparticles using tumor cells. Therefore, we focused on the antitumor activity of cisplatinincorporated nanoparticles of PAA-MMA copolymer. We obtained significantly smaller particles incorporating cisplatin than Yan and Gemeinhart's study, ${ }^{10}$ ie, cisplatinincorporated nanoparticles of PAA-MMA copolymer in this study had smaller average particle size - less than $170 \mathrm{~nm}$. 


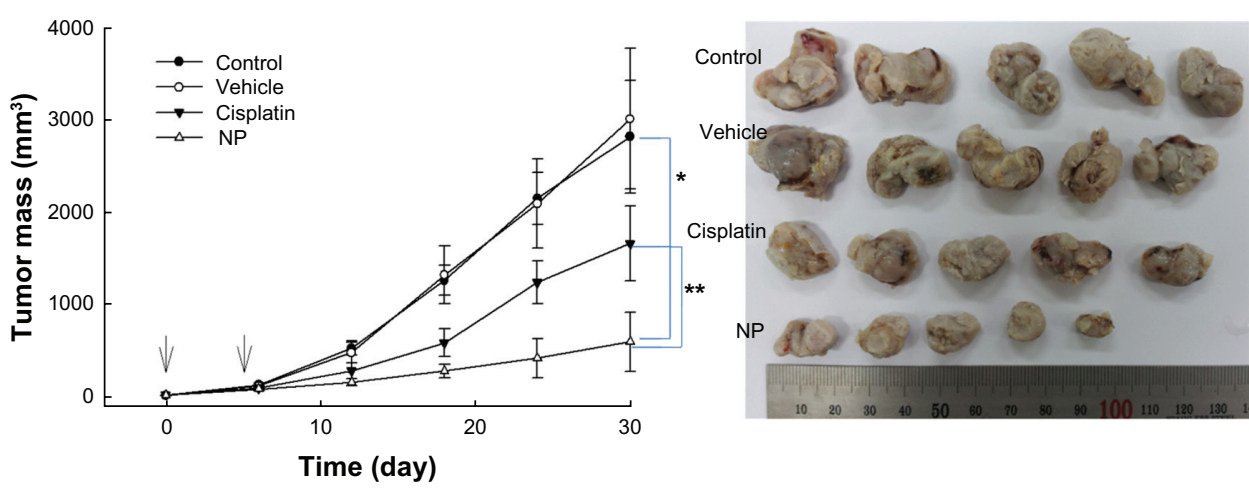

Figure 8 Changes of tumor mass after administration of cisplatin or cisplatin-incorporated (poly[acrylic acid-co-methyl methacrylate]-2-3) nanoparticles (NPs). CT26 cells were implanted into the backs of mice, and drug was injected after 2 weeks of tumor-cell implantation. The time for first drug injection was determined as day 0 . Drug injection was done twice at an interval of 4 days. Phosphate-buffered saline was injected into control mice. Cisplatin or NPs (dose: 5 mg/kg) were administered via the tail vein. The vehicle was administered with poly(acrylic acid-co-methyl methacrylate)-2 $(50 \mathrm{mg} / \mathrm{kg})$ into the mice. Five mice were used for each group. Note: $* * * P<0.001$.

Nanoparticles smaller than $200 \mathrm{~nm}$ are believed to be an appropriate vehicle for prevention of reticuloendothelial system uptake and for passive targeting to specific organs. ${ }^{13-15}$ Therefore, the cisplatin-incorporated nanoparticles in this study may be more suitable for antitumor drug targeting than the microparticles of Yan and Gemeinhart's study. ${ }^{10}$ The higher AA content in the copolymer composition may have higher potential to form a complex with cisplatin. We were able to obtain stable nanoparticles at a polymer:cisplatin weight ratio of less than 100:20 mg, as shown in Table 2 . Significant aggregation or precipitants were observed when cisplatin feeding weight was higher than $30 \mathrm{mg}$. Sustained release of cisplatin from nanoparticles was observed in in vitro drug-release studies while free cisplatin was rapidly liberated from dialysis membrane as shown in Figure 4, indicating that PAA-MMA nanoparticles are promising vehicles as sustained release formulations.

PAA-MMA nanoparticles showed similar anticancer activity against CT26 tumor cells in vitro, as shown in Figures 5-7, while PAA-MMA copolymer did not solely affect the growth of tumor cells. Furthermore, cisplatin-incorporated nanoparticles induced apoptosis/necrosis of tumor cells as well as free cisplatin. PAA-MMA copolymer did not affect the apoptosis/necrosis process of tumor cells at equivalent doses of nanoparticle treatment. In contrast to the in vitro study, cisplatin-incorporated nanoparticles showed improved antitumor activity in vivo using animal tumor-bearing mice. These results might be due to the fact that sustained-release properties of nanoparticles render longer half-lives of cisplatin in blood, and then cisplatin concentration must be preferentially increased in the tumor tissue. ${ }^{5,12}$ Furthermore, enhanced permeation and retention of nanoparticles against solid tumors may contribute to these results. ${ }^{13,14}$ Liposomal carriers for cisplatin were reported to have potential in reduction of acute toxicity, increase in half-lives, and improvement of antitumor effects of cisplatin. ${ }^{7,16}$ In particular, cisplatin-incorporated polymeric micelles with intravenous administration were demonstrated to have higher and longer serum levels than free cisplatin. ${ }^{17}$ Thus, treatment with polymeric micelle or colloidal carriers against solid-tumor bearing mice can reduce nephrotoxicity with promising anticancer activity. ${ }^{4,5,12,17}$ Furthermore, many reports have described the relationship between improved anticancer activity and longer blood-circulation time of colloidal carriers with small particle sizes..$^{5-7,12-17}$ Since PAA-MMA nanoparticles in the present study also had small particle sizes and sustainably released cisplatin to the aqueous phase, these nanoparticles might also have longer half-lives in biological systems, inducing improved anticancer activity.

In conclusion, cisplatin-incorporated nanoparticles were fabricated using PAA-MMA copolymer through an ioncomplex formation, and the antitumor activity of these nanoparticles was assessed against CT26 colon carcinoma cells in vitro and in vivo. PAA-MMA nanoparticles incorporating cisplatin were spherical, less than $200 \mathrm{~nm}$ in size, and showed sustained-release properties. The improved antitumor activity of cisplatin-incorporated nanoparticles was observed with a animal tumor xenograft model. We suggest that cisplatinincorporated nanoparticles of PAA-MMA copolymer are a promising candidate for antitumor drug delivery.

\section{Acknowledgment}

This work was partially supported by a grant-in-aid (PJ008445) for scientific research from the Ministry for Food, Agriculture, Forestry and Fisheries of South Korea. 


\section{Disclosure}

The authors report no conflicts of interest in this work.

\section{References}

1. Rosenberg B. Platinum complexes for the treatment of cancer. Interdisc Sci Rev. 1978;3:134-147.

2. Kartalou M, Essigmann JM. Mechanism of resistance to cisplatin. Mutat Res. 2001;478:23-43.

3. Ponzani V, Bressolle F, Haug IJ, Galtier M, Blayac JP, Balmès P. Cisplatin-induced renal toxicity and toxicity-modulating strategies: a review. Cancer Chemother Pharmacol. 1994;35:1-9.

4. Nishiyama N, Kataoka K. Preparation and characterization of size-controlled polymeric micelle containing cisdichlorodiammineplatinum(II) in the core. J Control Release. 2001; 74:83-94.

5. Nishiyama N, Okazaki S, Cabral H, et al. Novel cisplatin-incorporated polymeric micelles can eradicate solid tumors in mice. Cancer Res. 2003;63:8977-8983.

6. Cheng L, Jin C, Lv W, Ding Q, Han X. Developing a highly stable PLGAmPEG nanoparticle loaded with cisplatin for chemotherapy of ovarian cancer. PLoS One. 2011;6:e25433.

7. Leite EA, Souza CM, Carvalho-Júnior AD, et al. Encapsulation of cisplatin in long-circulating and $\mathrm{pH}$-sensitive liposomes improves its antitumor effect and reduces acute toxicity. Int $J$ Nanomedicine. 2012;7:5259-5269.

8. Sonoda A, Nitta N, Nitta-Seko A, et al. Complex comprised of dextran magnetite and conjugated cisplatin exhibiting selective hyperthermic and controlled-release potential. Int J Nanomedicine. 2010;5:499-504.
9. Li C, Yang DJ, Nikiforow S, et al. Formation and characterization of cisplatin-loaded poly(benzyl L-glutamate) microspheres for chemoembolization. Pharm Res. 1994;11:1792-1799.

10. Yan X, Gemeinhart RA. Cisplatin delivery from poly(acrylic acidco-methyl methacrylate) microparticles. J Control Release. 2005;106: $198-208$.

11. Jeong YI, Kim ST, Jin SG, et al. Cisplatin-incorporated hyaluronic acid nanoparticles based on ion-complex formation. J Pharm Sci. 2008;97:1268-1276.

12. Plummer R, Wilson RH, Calvert H, et al. A phase I clinical study of cisplatin-incorporated polymeric micelles (NC-6004) in patients with solid tumours. Br J Cancer. 2011;104:593-598.

13. Maeda H. Macromolecular therapeutics in cancer treatment: the EPR effect and beyond. J Control Release. 2012;164:138-144.

14. Bae YH. Interview with Dr You Han Bae: Ligand-mediated versus 'passive' targeting approaches in nanoparticle oncology research. Ther Deliv. 2012;3:933-936.

15. Allemann E, Gurny R, Doelker E. Drug-loaded nanoparticles preparation methods and drug targeting issues. Eur J Pharm Biopharm. 1993;39:173-191.

16. Stathopoulos GP, Boulikas T, Vougiouka M, et al. Pharmacokinetics and adverse reactions of a new liposomal cisplatin (Lipoplatin): phase I study. Oncol Rep. 2005;13:589-595.

17. Mizumura Y, Matsumura Y, Hamaguchi T, et al. Cisplatin-incorporated polymeric micelles eliminate nephrotoxicity, while maintaining antitumor activity. Jpn J Cancer Res. 2001;92:328-336.
International Journal of Nanomedicine

\section{Publish your work in this journal}

The International Journal of Nanomedicine is an international, peerreviewed journal focusing on the application of nanotechnology in diagnostics, therapeutics, and drug delivery systems throughou the biomedical field. This journal is indexed on PubMed Central, MedLine, CAS, SciSearch ${ }^{\circledR}$, Current Contents ${ }^{\circledR} /$ Clinical Medicine,

\section{Dovepress}

Journal Citation Reports/Science Edition, EMBase, Scopus and the Elsevier Bibliographic databases. The manuscript management system is completely online and includes a very quick and fair peer-review system, which is all easy to use. Visit http://www.dovepress.com/ testimonials.php to read real quotes from published authors. 